Elkes, J. J., Frazer, A. C., Schulman, J. H. \& Stewart, H. C. (1945). In the Press.

Frazer, A. C. (1938). Analyst, 63, 308.

Frazer, A. C. (1943a). J. Physiol. 102, 306.

Frazer, A. C. (1943b). J. Physiol. 102, 329.

Frazer, A. C., Schulman, J. H. \& Stewart, H. C. (1944). J. Physiol. 108, 306.

Frazer, A. C. \& Stewart, H. C. (1937). J. Physiol. 90, 18.

Grün, A. \& Corelli, O. (1912). J. chem. Soc. p. 409.

Kostyal, L. (1926). Mag. orv. Arch. 27, 276.
Macfarlane, M. G. \& Knight, B. C. J. G. (1941). Biochem. J. $35,884$.

Mellanby, J. (1925). J. Physiol. 60, 85.

Robinson, C. S. (1935). J. biol. Chem. 108, 403.

Smith, G. F. \& Duke, F. R. (1941). Industr. Engng Chem. (Anal. ed.), 13, 558.

Verzar, F. \& McDougall, E. J. (1936). Absorption from the Intestine. London: Longmans, Green and Co.

West, E. S., Hoagland, C. L. \& Curtis, G. H. (1934). J. biol. Chem. 104, 627.

Willstätter, R., Waldschmidt-Leitz, E. \& Memmen, F. (1922). Hoppe-Seyl. Z. 125, 93.

\title{
The Thermal Destruction of Vitamin $B_{1}$
}

\section{THE INFLUENCE OF BUFFER SALTS ON THE RATE OF DESTRUCTION OF ANEURIN AT $100^{\circ}$}

\author{
By K. T. H. FARRER, Research Division, Kraft Walker Cheese Co. Proprietary Ltd., \\ Melbourne, Australia
}

(Received 3 January 1945)

The rate of destruction of aneurin in boiling solutions at various $\mathrm{pH}$ values has been described by Farrer $(1941 a)$. It was realized that the work done was, in effect, the study of a first order reaction, but a formal mass-action study was not published. Traill (1941) subsequently pointed out that if $\log k$ (where $k$ is the velocity coefficient) is plotted against $\mathrm{pH}$ (also a logarithmic function), the curve shown in Fig. 1 results. The relation is linear until $\mathrm{pH} 7$ is reached, after which the curve rises more steeply. Further work on this problem was not possible until recently. A reference to some work by Beadle, Greenwood \& Kraybill (1943), who claim that aneurin is destroyed at different rates in different buffer solutions, focused attention on the fact that in the work previously published two buffer solutions were used, the McIlvaine phosphate-citric acid buffer for $\mathrm{pH} \mathrm{3,4,5}$ and 6, and the Kolthoff phosphate-borate buffer for pH 7, 8 and 9. Booth (1943), too, using phosphate and phthalate buffers, noted rates of destruction smaller than those described earlier (Farrer, 1941 $a$ ), and suggested that the buffer used in that work contained some impurity which catalyzed the destruction of aneurin. This was not so, and it was immediately realized that the change in slope of the curve shown in Fig. 1 could be due to the occurrence of two different straight lines, one for each buffer solution. This explanation of the change of slope has been proved correct by further experimental work, and it has been found that other buffer solutions also show a linear relation between $\mathrm{pH}$ and $\log k$. Furthermore, it has been found that the slope of the curve obtained by plotting $\mathrm{pH}$ against $\log k$ varies with the buffer solution used and with the predominating ions present.

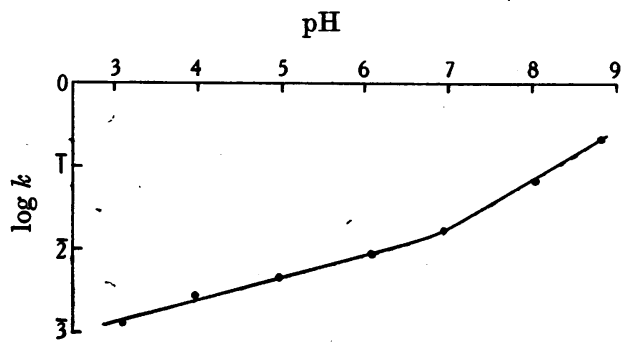

Fig. 1. $\mathrm{pH} / \log k$ curve for the $\mathrm{pH}$ values studied earlier (Farrer, 1941 a).

\section{EXPERIMENTAL}

The method of attack was the same as that previously reported. $25 \mathrm{ml}$. of aneurin stock solution were added to $200 \mathrm{ml}$. of the buffer solution and the $\mathrm{pH}$ precisely determined. The solution was then boiled under reflux, and samples were withdrawn at regular intervals, cooled as rapidly as possible, and the aneurin content determined by the Jansen thiochrome method.

Aneurin stock solution. Several different solutions were used throughout this work, but all were made by dissolving about $10 \mathrm{mg}$. of pure vitamin $B_{1}$ (obtained from Bayer Pharma Proprietary Ltd., Sydney) in $250 \mathrm{ml}$. of water distilled in glass. As previously reported, two or three drops of $\mathrm{HCl}$ added to these stock solutions render them stable for at least 3 months. 
Buffer solutions. The following solutions were used: (a) citric acid, $0.1 \mathrm{M}$; (b) disodium hydrogen phosphate, $0.2 \mathrm{M} ;(c)$ potassium dihydrogen phosphate, $0.1 \mathrm{M} ;(d)$ sodium diborate, $0.05 \mathrm{M}$; $(e)$ succinic acid, $0.05 \mathrm{M}$; $(f)$ sodium dihydrogen phosphate, $\mathrm{M} / 15$; $(g)$ disodium hydrogen phosphate, $\mathbf{M} / \mathbf{1 5}$. All solutions were made from Analar chemicals and distilled water. The McIlvaine series was made from solutions $(a)$ and $(b)$; the Kolthoff series from $(c)$ and $(d)$ for phosphate-borate, and from $(d)$ and $(e)$ for boratesuccinic acid; and the Sorensen series from $(f)$ and $(g)$.

Analytical method. The method of determination of aneurin and the apparatus employed were the same as were used previously, and have been described elsewhere (Farrer, $1941 b)$. Only one modification was introduced. Whereas in the previous work the $n$-butanol phase was dried over anhydrous $\mathrm{Na}_{2} \mathrm{SO}_{4}$, the modification of Wang \& Harris (1939) was now employed. After the separation of the phases, $10 \mathrm{ml}$. of the $n$-butanol layer were pipetted into a clean dry Errlenmeyer flask $(50 \mathrm{ml}$.), and clarified by the addition of exactly $2 \mathrm{ml}$. of ethanol. The fluorescence could then be read immediately. This modification permitted a great saving in time.

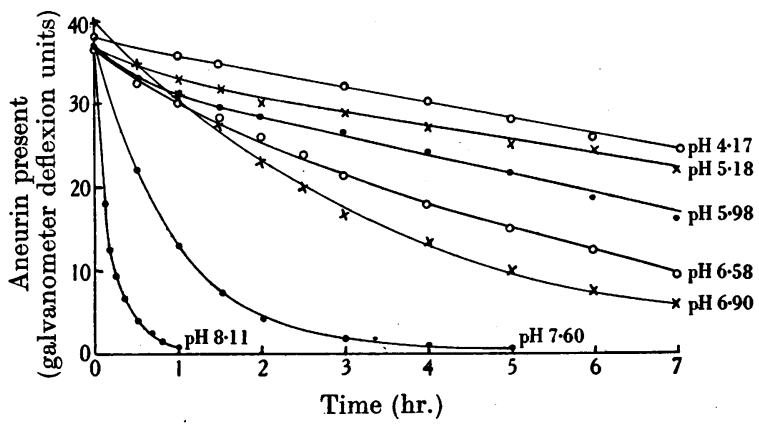

Fig. 2. Destruction of aneurin in boiling Kolthoff succinic acid-borate buffer. conclusion of each experiment, the $\mathrm{pH}$ was again determined on the solution used, and in almost every case any change in $\mathrm{pH}$ was within experimental error.

The solution was boiled in a $300 \mathrm{ml}$. Erlenmeyer flask connected to a Davies condenser by means of a ground-glass joint. Samples were withdrawn at given time intervals by means of a pipette, transferred to a $50 \mathrm{ml}$. Erlenmeyer flask, and cooled rapidly in rúnning water. $5 \mathrm{ml}$. quantities were used for aneurin determinations. The ground-glass apparatus was preferred, even though the taking of samples was more cumbersome than in the case of the wash-bottle arrangement used previously and for the solutions of higher $\mathrm{pH}$ in this work.

(b) $\mathrm{pH} 7 \cdot 5-8 \cdot 3$. The procedure previously described was used. In each case $25 \mathrm{ml}$. of aneurin stock solution were added from a pipette to a known volume of the boiling buffer solution, and a stop-watch was started when half had run in. The wash-bottle arrangement carried in a cork stopper was used, and samples were blown into $50 \mathrm{ml}$. Erlenmeyer flasks when the exact time had elapsed. Each sample was quickly cooled, and oxidized immediately with ferricyanide solution.

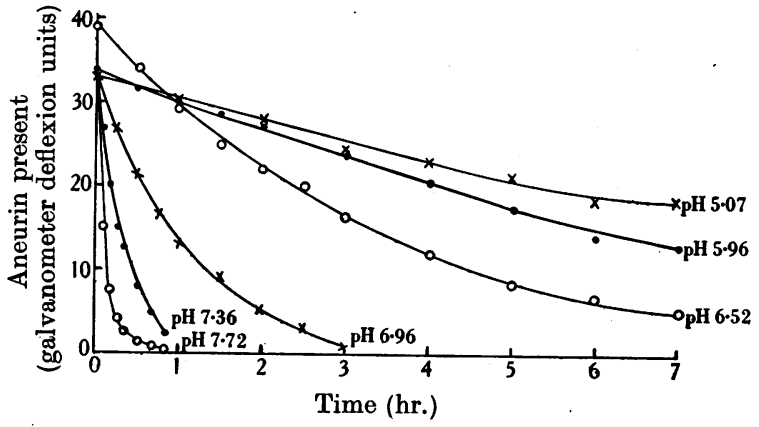

Fig. 3. Destruction of aneurin in boiling Sorensen phosphate buffer.

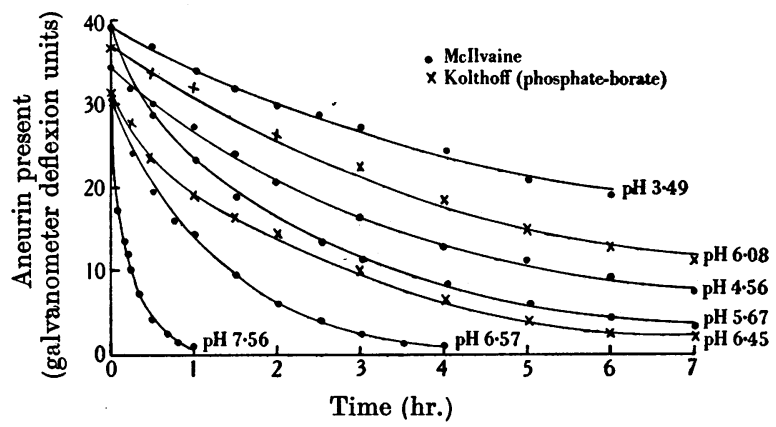

Fig. 4. Destruction of aneurin in boiling McIlvaine citric acid-phosphate, and Kolthoff phosphate-borate buffers.

\section{Experimental procedure}

(a) $\mathrm{pH} \mathrm{3-7 \cdot 5.} 25 \mathrm{ml}$. of aneurin stock solution were added to $200 \mathrm{ml}$. of the desired buffer solution and the exact $\mathrm{pH}$ was determined by means of a Cambridge portable pH meter. Both glass and quinhydrone electrodes were used in this work, and comparisons always gave good agreement. An accuracy of $\pm 0.02 \mathrm{pH}$ units is claimed. At the

\section{RESULTS}

As in the earlier work, results have been expressed graphically (Figs. 2-4) by plotting galvanometer readings of the fluorimeter against time. Those obtained for the four McIlvaine and the three Kolthoff phosphate-borate buffer solutions used in the earlier 
work are not repeated in this paper, but those for the intermediate $\mathrm{pH}$ values with these buffers are grouped together in Fig. 4. Calculations based on the earlier results are included in this work. To avoid confusion, four curves have been omitted from the graphs: the McIlvaine buffer curve at pH 8.07, which is almost the same as the Kolthoff boratesuccinic acid curve at $\mathrm{pH} 8 \cdot 11$; the Kolthoff phosphate-borate curves for $\mathrm{pH} \mathbf{7 \cdot 5 6}$ and 8.32 , which are very similar to the Sorensen phosphate curves pH 7.36 and 7.72 respectively; and the Sorensen phosphate curve at $\mathrm{pH} 5 \cdot 50$, which is virtually coincident with the same buffer curve at pH 5.07.

The barometer reading was noted for each experiment, and from the atmospheric pressure and the boiling-point elevation of water the actual boiling-point of each solution has been calculated.

Even in the case of the greatest deviation, the error was only $\pm \mathbf{0} \cdot 25^{\circ}$, and in most cases was very much less, so -that temperature variations may be neglected and the temperature regarded as constant at $100^{\circ}$.

\section{Interpretation of results}

For a monomolecular reaction, the velocity coefficient, $k$, is given by the mass-action equation

$$
k=\frac{2 \cdot 303}{t} \log _{10} \frac{a}{a-x},
$$

where $t$ is the time expressed in convenient units (usually minutes), $a$ is the initial concentration, and $x$ is the amount which has undergone change in time, $t ;(a-x)$ is thus the concentration remaining after time, $t$, and at any given time is directly pro: portional to the galvanometer deflexion of the fluorimeter. The initial concentration, $a$, for each experiment is obviously given by the deflexion when $t=0$.

For each buffer solution, time, $t$, has been plotted against $\log _{10}(a-x)$, and a straight line has been obtained (Fig. 5). In many cases the reaction velocity was greater at first than the steady value ultimately reached. This was particularly noticeable at $\mathrm{pH}$ values greater than $7 \cdot 0$, and with most of the McIlvaine (phosphate-citric acid) buffer solutions.

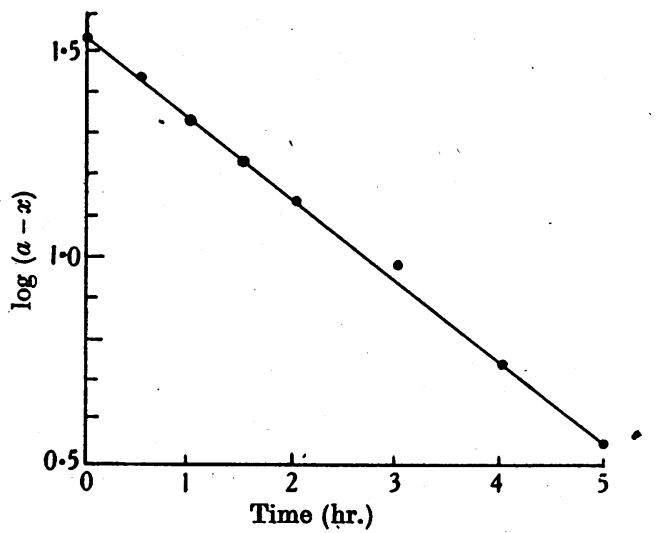

Fig. 5. Typical monomolecular reaction curve obtained for destruction of aneurin in boiling buffer solutions.

Nearly every Kolthoff buffer solution of $\mathrm{pH} 7 \cdot \overline{0}$ or less gave a steady velocity coefficient over the whole curve. In one or two cases, e.g. Kolthoff borate-

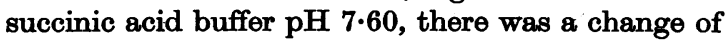
slope at the end of the experiment, but this could be readily accounted for by experimental error in reading the feeble fluorescence remaining, small variations in the galvanometer readings causing large differences in $\log (a-x)$. The time required for the reaction to settle down was never more than an hour and generally was much less.

The steady straight line in each case was used to determine $\log (a-x)$ at different time intervals, and from these figures $k$ has been calculated. The values obtained for $k$ and $\log k$ are tabulated (see Table 1).

\section{Table 1. Values of the velocity coefficient for the thermal destruction of aneurin} obtained at different $\mathrm{pH}$ 's with different buffer mixtures

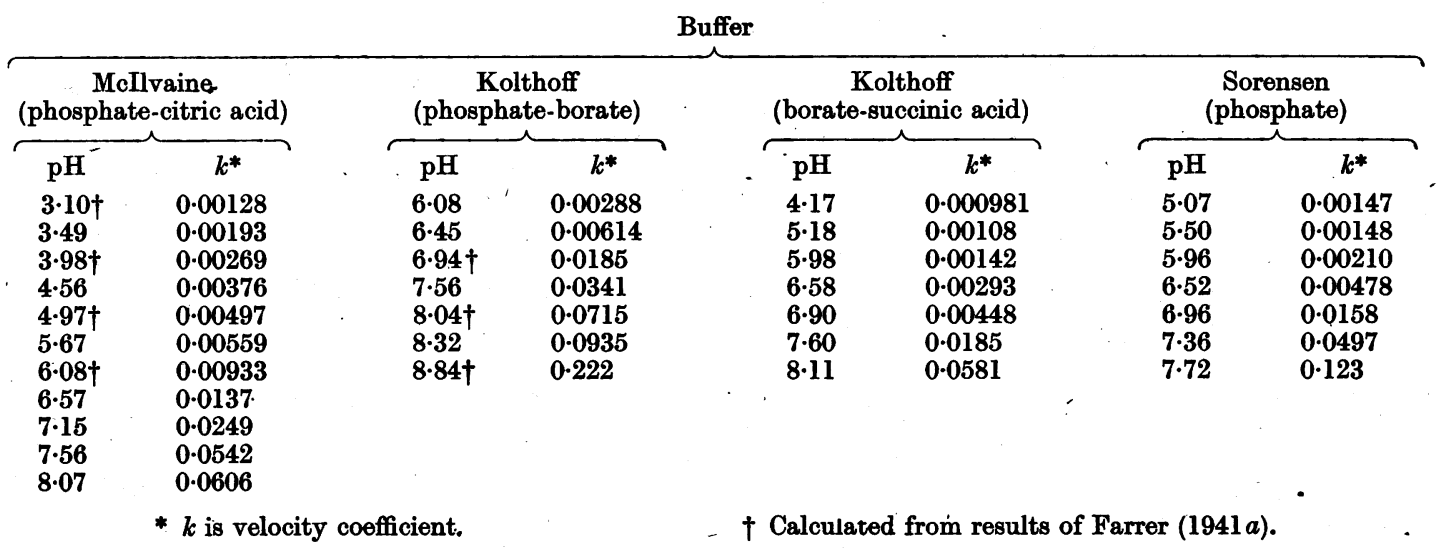


Log $k$ has been plotted against $\mathrm{pH}$ for each buffer solution (Fig. 6), and the curves obtained approximate roughly to straight lines. The velocity coefficient is usually inversely proportional to the hydrogen-ion concentration, and the magnitude of the effect is dependent on the nature of the buffer salts present. In order to predict the behaviour of aneurin on boiling in any given solution, it is therefore necessary to know not only the pH but also the buffer salts producing that $\mathrm{pH}$.

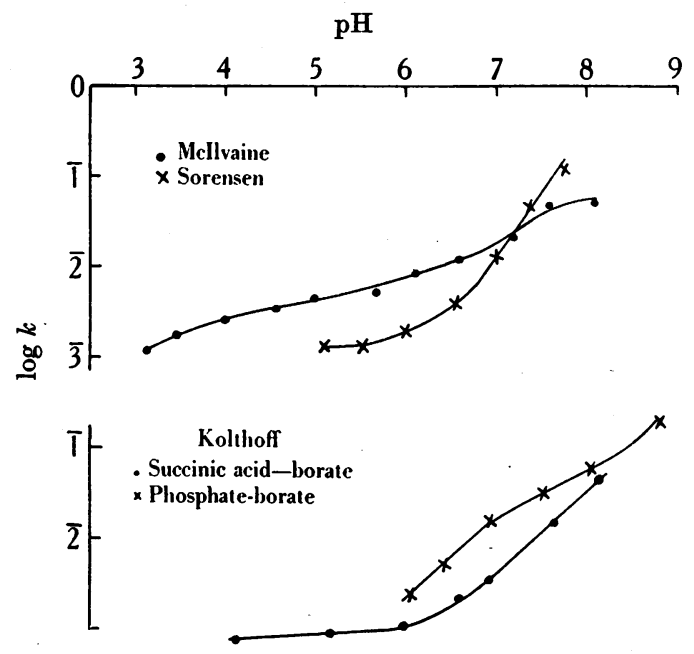

Fig. 6. $\mathrm{pH} / \log k$ curve for destruction of aneurin in four buffer. solutions

Two of the buffers, viz. the McIlvaine and the Kolthoff phosphate-borate buffers, give flattened sigmoid curves approximating to, but not coinciding with, straight lines. The curves for the Sorensen and Kolthoff succinic acid-borate buffers consist of two separate and distinct straight lines. Moreover, there is a close analogy between the course of the curve obtained by plotting $\mathrm{pH}$ against $\log k(\mathrm{pH} / \log k$ curve) and the course of the titration curve for the buffers employed. Points of inflexion appear at approximately the same $\mathrm{pH}$ values,

With the Sorensen phosphate and Kolthoff succinic acid-borate buffers, the buffering action lies in the range $\mathrm{pH} 5 \cdot 9-8 \cdot 0$ and $3 \cdot 0-5 \cdot 8$ respectively, where straight lines occur on the $\mathrm{pH}$ titration curves. Although succinic acid has two ionizable hydrogen atoms, the two dissociation constants are too close to produce any visible discontinuity in the titration curve. In the $\mathrm{pH} / \log k$ curves there are similar straight lines in the same $\mathrm{pH}$ ranges. If the $\mathrm{pH}$ of the Sorensen buffer is moved to the acid side of the lower limit of the buffer range and that of the Kolthoff buffer to the alkaline side, the buffer curve in each case shows a change in direction, and, at approximately the same $\mathrm{pH}$ value, so does the
$\mathrm{pH} / \log k$ curve. In the McIlvaine and Kolthoff phosphate-borate buffers, citric acid and sodium diborate respectively are used to smooth out the curve obtained in the well-known titration of phosphoric acid with sodium hydroxide. Nevertheless, the resulting curves are not perfectly straight lines but are flattened sigmoid curves. Similarly, as noted above, the $\mathrm{pH} / \log k$ curves for these buffers are flattened sigmoid curves which show discontinuities at approximately the same $\mathrm{pH}$ values as in the corresponding buffer curves.

There are, then, two similar sets of curves, and, in each, one axis is $\mathrm{pH}$. In the case of the buffer titration curves, the other axis can be regarded as an indirect indication of the ionic environment of the solutions, points of inflexion corresponding with significant changes in the ionic constitution. It is therefore logical to link these changes with the discontinuities appearing at similar $\mathrm{pH}$ values in the $\mathrm{pH} / \mathrm{log} k$ curve. It can then be stated that the rate of destruction of aneurin changes as the ionic constitution changes with rising $\mathrm{pH}$. However, this change in the rate of destruction of aneurin is not solely dependent on the ionic environment, but is also conditioned by the $\mathrm{pH}$ in that where the change in the nature of the ions present in the solution is accompanied by a significant change in $\mathrm{pH}$ there is a significant change in the rate of destruction of aneurin, i.e. there is a definite change in the slope of the $\mathrm{pH} / \log k$ curve; but where the $\mathrm{pH}$ is only slightly affected by the changing ionic constitution of the solution there is a correspondingly slight change in the rate at, which aneurin is destroyed, i.e. there is only a slight inflexion in the $\mathrm{pH} / \log k$ curve.

In comparing buffer titration curves at room temperature with the rate of destruction of aneurin at $100^{\circ}$, account must be taken of possible changes in the dissociation constants. It should therefore be pointed out, first, that the results recorded in the literature (Landolt \& Börnstein, 1923) show that the change of dissociation at $100^{\circ}$ is small for all the acids studied, and, secondly, that the points of inflexion on the $\mathrm{pH} / \log k$ curves do not coincide exactly with those on the buffer titration curves at room temperature.

The curves published by Booth (1943) have been analyzed according to the method described in this paper. Since the actual figures were not recorded, each point on the curves was transferred to graph paper by means of a pair of dividers and the values obtained were taken as $(a-x)$. $\log (a-x)$ was then plotted against time, and $k$ and $\log k$ were calculated from the straight lines obtained. $\log k$ for pH $7 \cdot 2$ and $\mathbf{7 \cdot 4}$ could not be calculated accurately enough, as there were too few points available. In Fig. 7 the $\mathrm{pH} / \log k$ curve for Booth's phosphate buffer is compared with that for phosphate buffer 
obtained in this work. The agreement is good when one considers the method by which $(a-x)$ was obtained, and also that Booth worked with $0.2 \mathrm{M}$ potassium phosphate, whereas the work recorded in this paper was carried out with $\mathrm{M} / 15$ sodium phosphate.

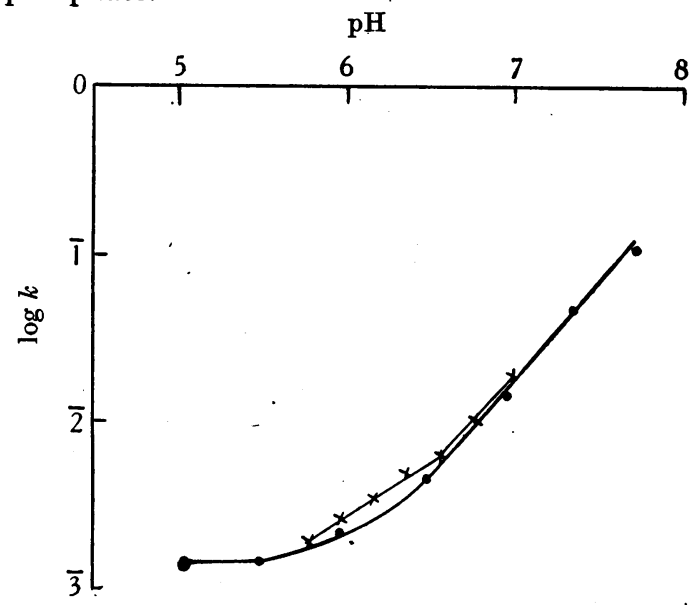

Fig. 7. $\mathrm{pH} / \log k$ curves for phosphate buffer. $(\mathrm{x})$ calculated from Booth's results. (•) results obtained in this work.

In a similar manner the values of $k$ and $\log k$ have been calculated for the phthalate buffer $(0 \cdot 2 \mathrm{M}$ potassium phthalate) and for the phosphate-phthalate mixture used by Booth (see Table 2).

If $\mathrm{pH} / \log k$ curves are plotted for these buffers it is found that the shape of the curve for the phthalate buffer closely follows that for the buffer curve for phthalic acid, and that the curve for the phosphatephthalate mixture also confirms the suggestions made herein.

In the light of the data presented in this paper, it is apparent that the explanation of the differences in the rates of destruction reported lies in the varying effect of the different ions present in the buffer solutions used by the various investigators.
Table 2. Velocity coefficients for the thermal destruction of aneurin calculated from Booth's results

\begin{tabular}{|c|c|c|c|}
\hline pH & $k^{*}$ & $\dot{\mathbf{p H}}$ & $k^{*}$ \\
\hline \multicolumn{4}{|c|}{ Phthalate buffer } \\
\hline $\begin{array}{l}2 \cdot 4 \\
3 \cdot 6 \\
4 \cdot 0 \\
4 \cdot 4 \\
4 \cdot 8\end{array}$ & $\begin{array}{l}0.00076 \\
0.0015 \\
0.0022 \\
0.0024 \\
0.0033\end{array}$ & $\begin{array}{l}5 \cdot 2 \\
5 \cdot 6 \\
6 \cdot 0 \\
6 \cdot 2\end{array}$ & $\begin{array}{l}0.0035 \\
0.0044 \\
0.0063 \\
0.0095\end{array}$ \\
\hline \multicolumn{4}{|c|}{ Phosphate-phthalate buffer } \\
\hline $\begin{array}{l}5 \cdot 4 \\
5 \cdot 8\end{array}$ & $\begin{array}{l}0.0022 \\
0.0031\end{array}$ & $\begin{array}{l}6 \cdot 4 \\
6 \cdot 8\end{array}$ & $\begin{array}{l}0.0065 \\
0.0126\end{array}$ \\
\hline
\end{tabular}

\section{SUMMARY}

1. The destruction of aneurin in boiling solution has been followed in various buffer solutions at $\mathrm{pH}$ values ranging from $3 \cdot 0$ to $8 \cdot 0$.

2. The methods used have been previously described, and the buffers studied were the Sorensen phosphate, the McIlvaine phosphate-citric acid, and the Kolthoff phosphate-borate and succinic acid-borate.

3. In general, it has been found that there is, for any given buffer, a linear relationship between the reaction velocity and the hydrogen-ion concentration, which can best be expressed by plotting $\mathrm{pH}$ against $\log k$, where $k$ is the velocity coefficient.

4. This relationship is different for each buffer, and the slope of the curve changes as the ionic constitution of the solution alters. Where this alteration is accompanied by a large change in $\mathrm{pH}$, there is a big change in the slope of the curve obtained by plotting $\mathrm{pH}$ against $\log k$, and vice versa.

5. In all cases, the velocity of the reaction increases as the $\mathrm{pH}$ rises.

The author wishes to thank the Directors of the Kraft Walker Cheese Co. Proprietary Ltd. for permission to publish this paper.

\section{REFERENCES}

Beadle, B. W., Greenwood, D. A. \& Kraybill, H. R. (1943). J. biol. Chem. 149, 339.

Booth, R. G. (1943). Biochem. J. 37, 518.

Farrer, K. T. H. (1941a). Aust. Chem. Inst. J. Proc. 8, 113.
Farrer, K. T. H. (1941 b): Aust. Chem. Inst. J. Proc. 8, 22. Landolt, H. \& Börnstein, R. (1923). Physikalisch-chemische Tabellnn. Berlin: Julius Springer.

Traill, R. C. (1941). Private communication.

Wang, Y. L. \& Harris, L. J. (1939). Biochem. J. 33, 1356. 